\title{
Majorana One-Tonne Cryostat Cooling Conceptual Feasibility Study
}

DJ Reid JL Orrell

JE Fast E Aguayo

April 2011

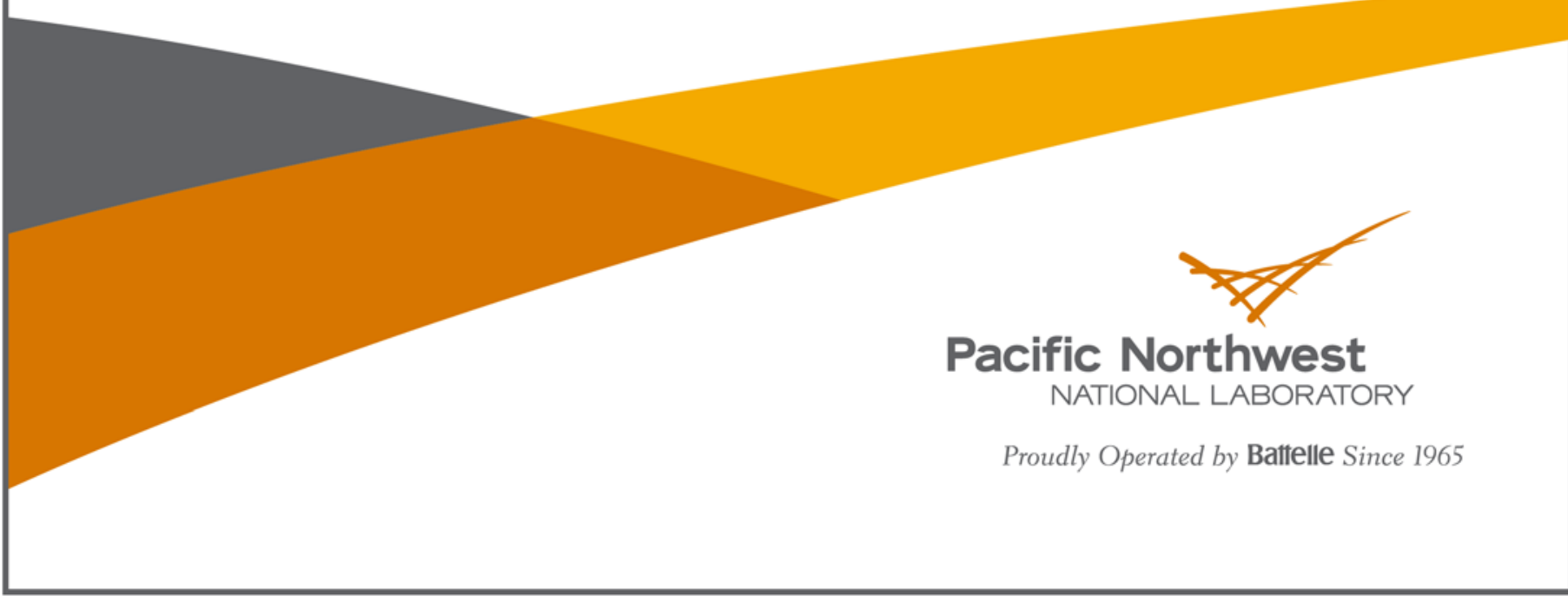




\title{
DISCLAIMER
}

This report was prepared as an account of work sponsored by an agency of the United States Government. Neither the United States Government nor any agency thereof, nor Battelle Memorial Institute, nor any of their employees, makes any warranty, express or implied, or assumes any legal liability or responsibility for the accuracy, completeness, or usefulness of any information, apparatus, product, or process disclosed, or represents that its use would not infringe privately owned rights. Reference herein to any specific commercial product, process, or service by trade name, trademark, manufacturer, or otherwise does not necessarily constitute or imply its endorsement, recommendation, or favoring by the United States Government or any agency thereof, or Battelle Memorial Institute. The views and opinions of authors expressed herein do not necessarily state or reflect those of the United States Government or any agency thereof.

\author{
PACIFIC NORTHWEST NATIONAL LABORATORY \\ operated by \\ BATTELLE \\ for the \\ UNITED STATES DEPARTMENT OF ENERGY \\ under Contract DE-AC05-76RL01830
}

Printed in the United States of America
Available to DOE and DOE contractors from the Office of Scientific and Technical Information, P.O. Box 62, Oak Ridge, TN 37831-0062; ph: (865) 576-8401 fax: $(865)$ 576-5728
email: reports@adonis.osti.gov

Available to the public from the National Technical Information Service 5301 Shawnee Rd., Alexandria, VA 22312 ph: (800) 553-NTIS (6847) email: orders@ntis.gov $<$ http://www.ntis.gov/about/form.aspx $>$ Online ordering: http://www.ntis.gov 


\section{Majorana One-Tonne Cryostat Cooling Conceptual Feasibility Study}

$\begin{array}{ll}\text { DJ Reid } & \text { JL Orrell } \\ \text { JE Fast } & \text { E Aguayo }\end{array}$

April 2011

Prepared for

the U.S. Department of Energy

under Contract DE-AC05-76RL01830

Pacific Northwest National Laboratory

Richland, Washington 99352 



\section{Summary}

This report evaluates the conceptual plans for a cryostat cooling design for the MAJORANA DEMONSTRATOR (MJD) one-tonne (S4) experiment. This document is based upon previous design work and experimental results used to evaluate the current MJD thermal design. A feasibility study of a cooling system for S4 based on the MJD thermosiphon experiment is presented. The one-tonne experiment will be a scaled up version of the MJD. There will be many cryostats in the S4 experiment. In this document a cryostat with up to 19 strings of germanium crystals is analyzed. Aside from an extra outer ring of crystals, the geometry of the cryostat for S4 is very similar to that for the MJD thermosiphon experiment. The materials used in the fabrication of both of these ultra-low background experiments will be underground-electroformed copper. The current MJD uses a two-phase liquid-gas cooling system to provide constant operating temperature. This document presents a theoretical investigation of a cooling system for the S4 experiment and evaluates the heat transfer performance requirements for such a system. 




\section{Acronyms and Abbreviations}

$\begin{array}{ll}\text { FEE } & \text { front-end electronics } \\ \text { FET } & \text { field-effect transistor } \\ \text { HPGe } & \text { high-purity germanium } \\ \text { HV } & \text { high voltage } \\ \text { IR } & \text { infrared radiation } \\ \text { LN } & \text { liquid nitrogen } \\ \text { MF } & \text { mass flow } \\ \text { MJD } & \text { MAJORANA Demonstrator } \\ \text { PEEK } & \text { polyether ether ketone } \\ \text { PNNL } & \text { Pacific Northwest National Laboratory } \\ \text { S4 } & \text { National Science Foundation Deep Underground Science and Engineering } \\ & \text { Laboratory Solicitation } 4\end{array}$





\section{Contents}

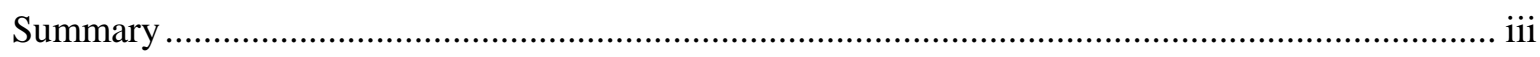

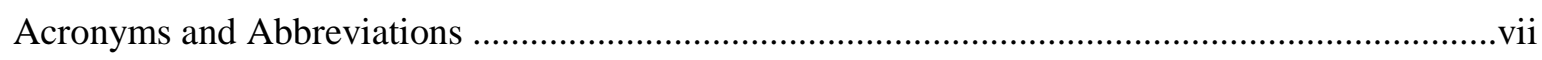

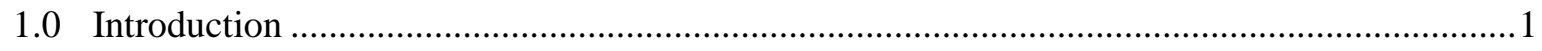

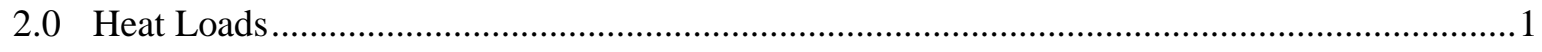

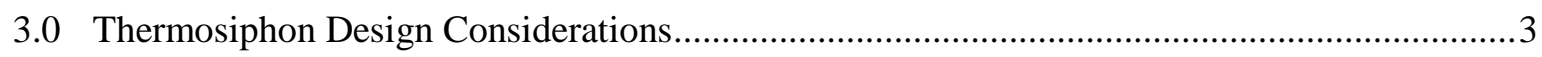

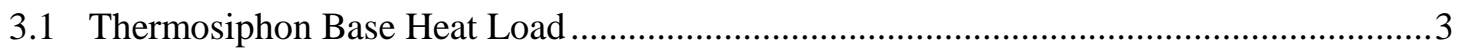

3.2 Initial Nitrogen Load...........................................................................................

3.3 Material Interface in the Detector Thermal Path..........................................................

3.4 Closed System Volume Considerations ..................................................................... 6

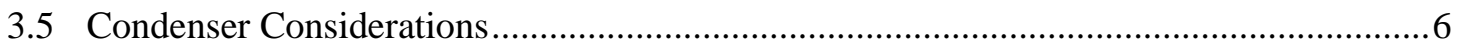

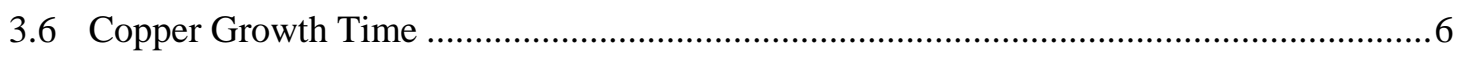

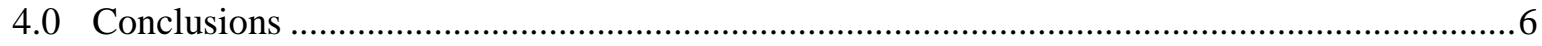

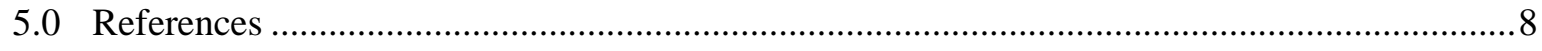

Appendix A Calculation of Radiated Heat Entering the S4 System from the Warm Cryostat WallsA.1 Appendix B Calculation of Conductive Heat Entering the System from the PEEK Supports ....... B.1 Appendix C Cable Heat Loads............................................................................................... 1 Appendix D Convective Heat Transfer Calculations for the Thermosiphon Experimental Setup .D.1 Appendix E Fluid Volume in the Copper Pipe ......................................................................... E.1

\section{Figures}

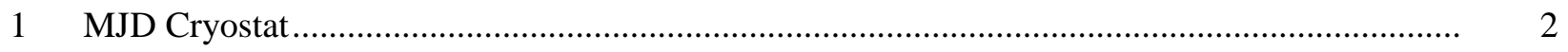

2 Translucent Cold Plate Section View ............................................................................... 2

3 Temperature Drop Across PNNL Thermosiphon Experiment's Thermal Joint Versus Tip

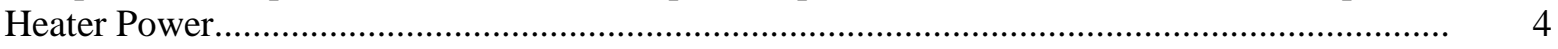

4 Heat Load Versus Temperature Drop Across the Thermosiphon Evaporator Tube .................... 5

\section{Tables}

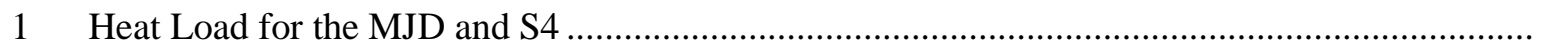





\subsection{Introduction}

The one-tonne ${ }^{76}$ Ge neutrinoless double-beta decay experiment (S4) will be a scaled-up version of the MAJORANA DEMONSTRATOR (MJD) [Aalseth et al. 2009]. The final detector array will have up to 19 strings of Germanium crystals per cryostat, a 180\% increase in detector capacity over the MJD. The number of channels will also be scaled up from 35 channels in the MJD to 95 channels in the one-tonne experiment. The geometry of both cryostats is very similar, both being cylindrical. The MJD cryostat has a diameter of $0.33 \mathrm{~m}$ (13 in). The cryostat for the one-tonne-scale experiment is expected to have a diameter of $0.43 \mathrm{~m}$ (17 in). The heights of both cryostats will be equal, at $0.43 \mathrm{~m}$ (17 in). The materials used in the fabrication of both ultra-low background experiments will be underground-electroformed copper. The current MJD uses a two-phase liquid-gas cooling system to provide constant operating temperature. The MJD cooling system is required to transport the heat $\sim 0.65$ meters ( $\sim \mathrm{ft}$ ) from the detectors located inside a lead and copper shield to a liquid-nitrogen Dewar container (Dewar) outside the shield. The S4 cryostat will have the same shield thickness. This document presents a theoretical investigation of a cooling system for the S4 experiment and evaluates the heat transfer performance requirements for such a system. The heat load for the S4 cryostat is calculated by summing the contributions from all thermal paths. The result is compared with the MJD heat load. Based on the calculated heat load, several thermosiphon design considerations are presented in the following sections. The heat leakage into the system through the thermosiphon arm is compared to that of the thermosiphon experimental setup presented in [Fast et al. 2010]. Issues such as the nitrogen load and description of the thermal path to the detector are also presented in the last section of this document.

\subsection{Heat Loads}

The heat load of the S4 cryostat has five components:

- radiation from the warm cryostat walls

- conduction through mechanical supports

- front-end electronics (FEE)

- conduction through electrical wiring

- heat leaks in the cooling-system arm and the nitrogen-expansion vessel.

Calculation of the heat leak due to radiation from the warm walls of the cryostat is described in Appendix A. The increase in diameter of the outer wall of the S4 cryostat relative to the nominal MJD design, and the subsequent increased surface area, raise the heat leakage into the detector from $2.3 \mathrm{~W}$ in the MJD to $3.1 \mathrm{~W}$ in S4. Figure 1 is a cross-sectional view of the MJD cryostat. It shows the MJD outer wall, the radiation shield between the detector modules and the external wall, and the detector strings.

The MJD cold plate is supported vertically by three cylindrical pins that tie into the cylindrical outer cryostat vessel. Calculation of the heat entering the system through the mechanical supports is described in Appendix B. For the S4 experiment, a scaling factor of 2.7 (based on a19/7 string ratio) can be used to obtain a new estimate based on the MJD architecture. For the calculations presented in Appendix B, the latest designs of the prototype cryostat of the MJD cold plate and support geometry are used. For the S4 experiment, twice the number of supports is assumed, to account for the increase in weight. These 
supports are made of PEEK (polyether ether ketone), a high-purity, low-conductivity plastic material. Figure 2 shows the detailed placement of these supports.

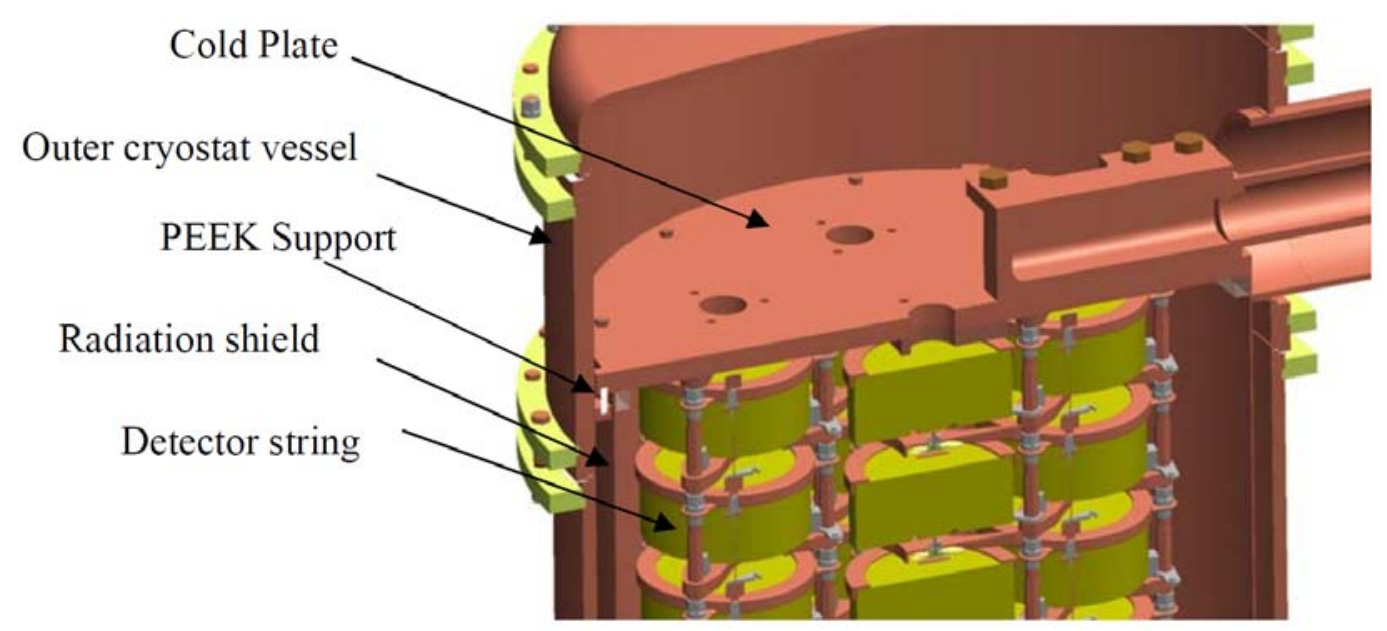

Figure 1. MJD Cryostat

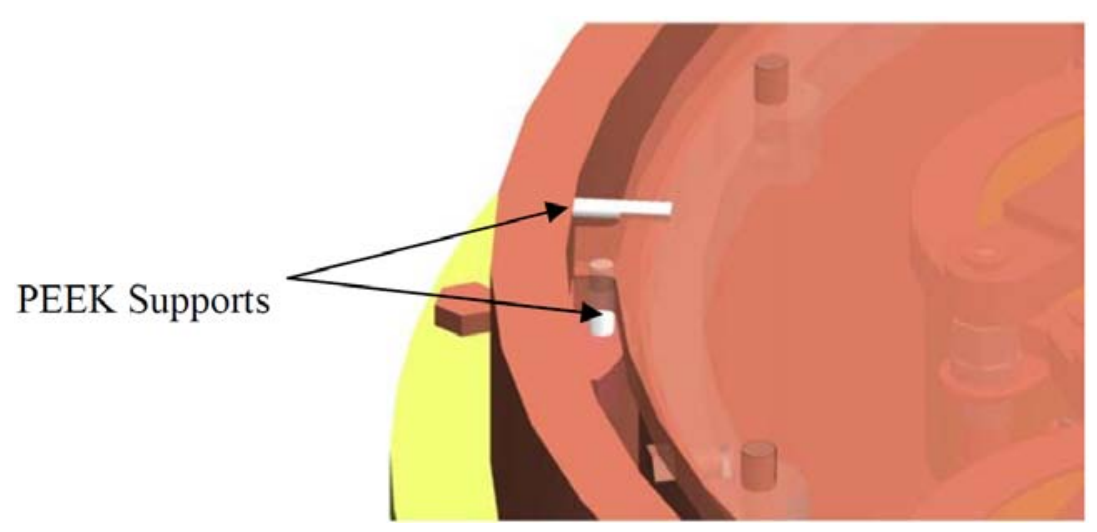

Figure 2. Translucent Section View of the Cold Plate

The MJD will hold seven strings of detectors for a total of 35 detector channels inside the cryostat; for the S4 experiment, the number of detector channels increases to 95. This number can be used to obtain a scaling factor for the electronics heat load from the MJD to the S4 experiments. The final designs of the FEE for both experiments are yet to be chosen. The two main components in the FEE that contribute to the heat load are the resistor used in the circuitry closing the baseline-restoring feedback loop and the field effect transistor (FET). The FET must be close to the crystal but the feedback resistor can be placed inside or outside the cryostat. There are the two possibilities: the resistor can be placed inside the cryostat, theoretically optimizing noise performance, or outside the cryostat, thus routing the length of the feedback line to the exterior. In the first case, the power dissipated by the FEE circuitry is estimated to be $100 \mathrm{~mW} / \mathrm{ch}$ [Miller 2010]. In the latter case, the power dissipated inside the detector is reduced to 40 $\mathrm{mW} / \mathrm{ch}$ [Luke 2010]. The total heat generated by the FEE is $9.45 \mathrm{~W}$ when the resistor is inside the cryostat and $3.78 \mathrm{~W}$ when the resistor is outside the cryostat. Table 1 presents the heat load components for MJD and S4 (assuming the higher-heat-load preamp option); this table combines the calculated heat 
loads (radiation, conduction and FEE) and experimental data to estimate the heat load for the final systems. A total increase in heat load of 30\% from the MJD experiment to the scaled-up S4 experiment is expected.

Table 1. Heat Load for the MJD and S4 (See text)

\begin{tabular}{|c|c|c|}
\hline & MJD & S4 \\
\hline Radiation (cryostat) (W) & 6.3 & 8.3 \\
\hline Conduction through supports (W) & 0.3 & 0.5 \\
\hline FEE (W) & 8 & 9.5 \\
\hline Radiation arm + conduction + arm supports ${ }^{(a)}(W)$ & 9.4 & 9.4 \\
\hline Total heat load (W) & 19.5 & 27.7 \\
\hline
\end{tabular}

(a) Measured experimentally with the thermosiphon prototype at PNNL

The thermal path from each detector through the electrical connections to the exterior must be accounted for in the final expected heat load. At this time there is insufficient information to determine these heat loads to a high degree of accuracy. The intent is to sink the cable heat load into the service body and avoid affecting the thermosiphon design. However, this will affect the overall load that must be handled by the Dewar. The results presented in Table 1 do not account for the cable heat load because these are not part of the thermosiphon's heat load. For the analysis of the expected cable load, see Appendix C.

\subsection{Thermosiphon Design Considerations}

\subsection{Thermosiphon Base Heat Load}

The thermosiphon consists of an evaporator section, a vertical column to create head pressure, and a condenser section. In order to operate safely in case of unanticipated warm-up, it is prudent to have a large gas-storage volume so that the volume change from evaporation of the working liquid at operating temperature does not result in excessive pressure in the sealed system. An estimate of the heat leaked into the system through the external Dewar connection, radiation from the vacuum jacket walls from the exterior to the inner detector chamber, and the nitrogen expansion vessel was derived in the PNNL thermosiphon experimental setup [Fast et al. 2010]. Figure 3 shows the temperature drop across the joint between the thermosiphon and the cold head versus the power applied at the tip. The heat leaking into the system as indicated from this linear regression was estimated to be $9.4 \mathrm{~W}$. 


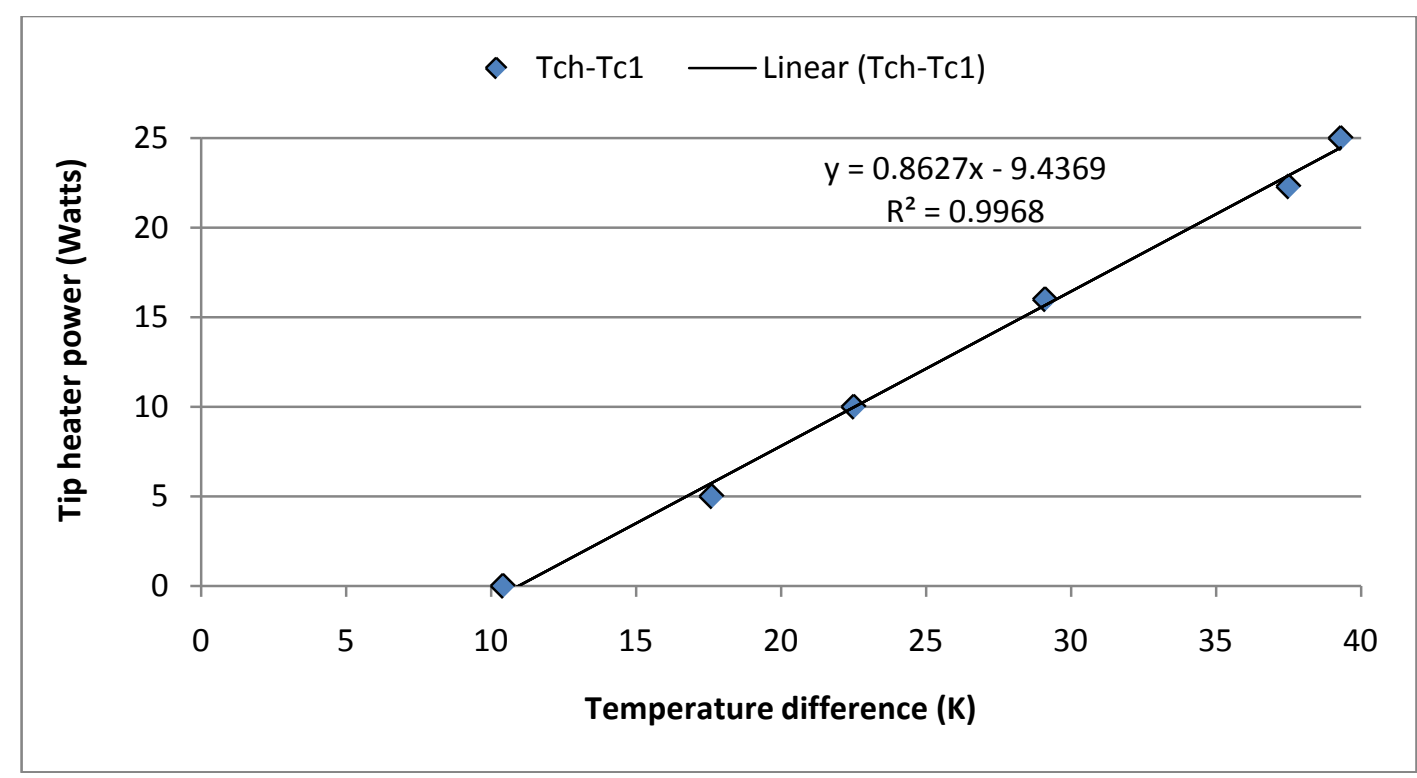

Figure 3. Temperature Drop Across PNNL Thermosiphon Experiment's Thermal Joint Versus Tip Heater Power [Fast et al. 2010]

\subsection{Initial Nitrogen Load}

The risks associated with the MJD thermosiphon apply to the scaled-up model. The two-phase system could induce microphonic vibration in the evaporator tube; these vibrations could be a significant source of noise. The amount of bubbling is proportional to the amount of liquid phase sitting in the evaporator tube. Minimizing the amount of nitrogen in the system would minimize the risk of microphonic induced noise. On the other hand, another risk to this system is that the heat load is too high, causing the liquid film to dry out, retreating back along the evaporator. The cold-plate interface is a poor conductor so the temperature increase along the dry section will be significant; therefore, the larger the quantity of liquid in the system, the smaller the risk that the tip of the evaporator tube will dry out. Figure 4 shows The temperature gradient across the evaporator tube can be estimated by comparing one of the top three lines in Figure 4 to the corresponding one of the bottom three lines in the graph.; from this curve the behavior of the two-phase system can be interpreted for the 15 pound-force per square inch gauge (psig) initialload case. The temperature gradient remains in a range of 5-7 K when the heat load is below $20 \mathrm{~W}$. A load in excess of $20 \mathrm{~W}$ causes the temperature gradient in the evaporator tube to exceed 13K. This temperature gradient points to a liquid dry-out at the tip of the evaporator tube. Flows in the gas and liquid phases are both laminar (see Appendix D). Calculation of the volume of fluid resting in the evaporator tube is described in Appendix E. 


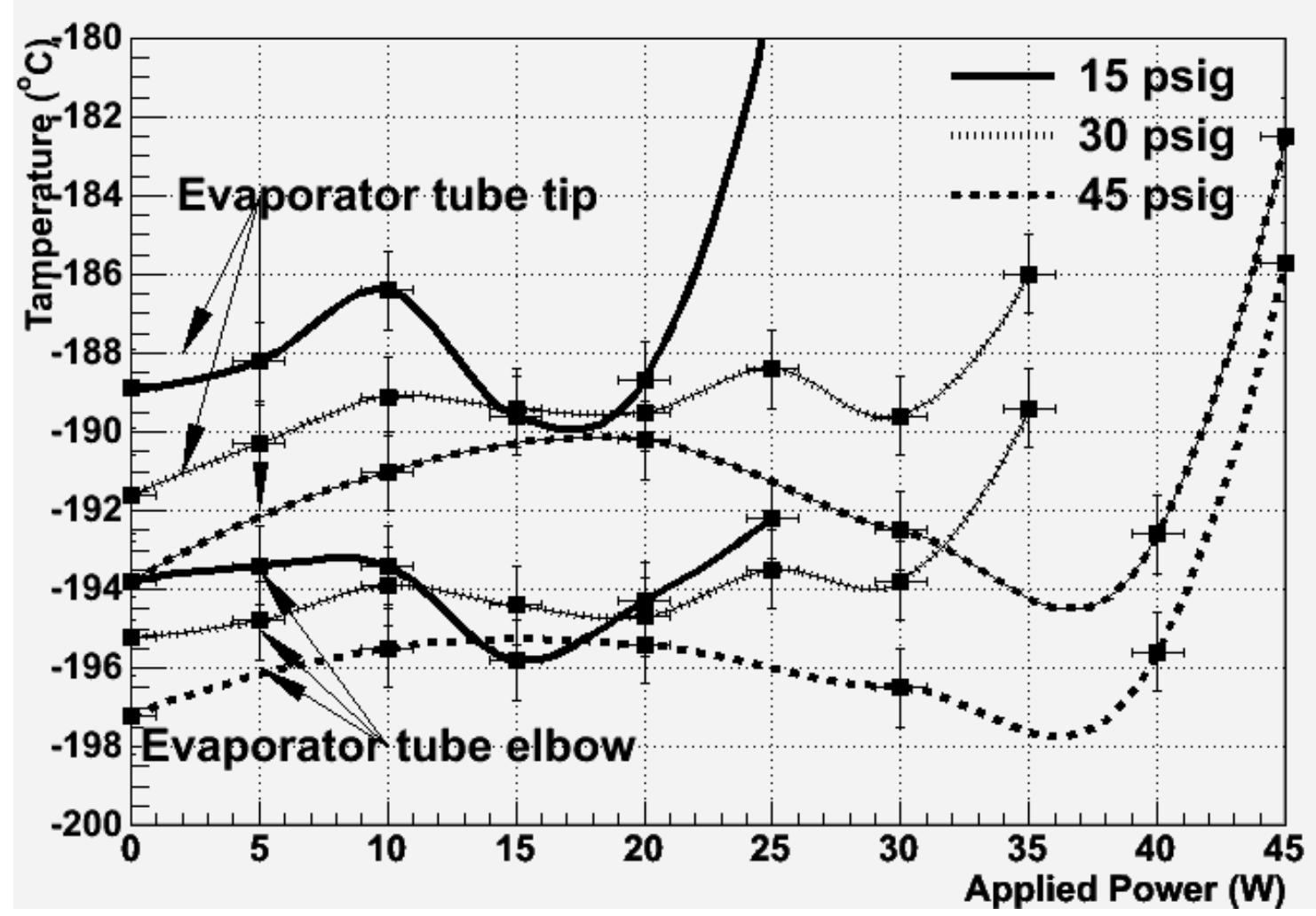

Figure 4. Heat Load Versus Temperatures at the Ends of the Evaporator Tube

If the nitrogen load is not matched to the maximum heat load, an increase in temperature along the thermal path will occur when the maximum heat load is presented to the cooling system. Based on Figure 4, since a stable operation in the $25 \mathrm{~W}$ heat load range is achieved with a nitrogen load of this is the recommended initial load for the S4 experiment in order to maintain constant temperature at $27.7 \mathrm{~W}$ of applied power.

\subsection{Material Interface in the Detector Thermal Path}

The thermal path from the liquid nitrogen bath in the Dewar (outside the shield) to the detector inside the cryostat crosses several interfaces. The condenser section of the Dewar and the cold-plate interface are two conductive interfaces that are in direct contact with the internal closed system. The Dewar interface can be made of low-resistivity, high-strength material such as aluminum 6061. The main contributor to the temperature gradient in each crystal thermal path is the cold-plate interface. Experiments for the characterization of the behavior of these thermal interfaces are being designed as part of the MJD development. The temperature rise through these joints will increase by the ratio of the $\mathrm{S} 4$ heat load to the MJD heat load (1.5 times). Since the temperature of the liquid-nitrogen (LN) bath is fixed, this implies a rise in the crystal temperatures. The expected temperature gradient across a material interface, given typical joint resistances of $1 / 2-1 \mathrm{~K} / \mathrm{W}$, will increase with the extra heat load presented by the $\mathrm{S} 4$ experiment. The extra $7 \mathrm{~W}$ of heat load in the S4 experiment means an extra $7 \mathrm{~K}$ or more in the ultimate detector temperature. This substantial increase can only be resolved by lowering the joint resistance or eliminating a thermal joint (e.g., the joint between the infrared (IR) shield and cold plate). 


\subsection{Closed System Volume Considerations}

Our calculation of the volumes in the closed system uses two assumptions: (1) the evaporator volume has a diameter of $2.4 \mathrm{~cm}$ and a length of $90 \mathrm{~cm}$, with a total internal volume of $407 \mathrm{cc}$; and (2) the fill volume is $10 \%$ liquid and $90 \%$ gas under normal operation. This results in a liquid volume of 41 cc. When the system is warm this liquid will evaporate, producing approximately 26 liters of nitrogen at standard temperature and pressure (STP). This suggests that the system should have a gas-storage volume of roughly 30 liters to accommodate the total gas load without excessive pressure.

\subsection{Condenser Considerations}

The condenser must be able to absorb both the evaporator heat load $(20 \mathrm{~W})$ and the cable heat load (32.3 W, see Appendix C) without producing excessive boiling that could generate microphonic noise in the detectors. The detector cables present a thermal path between detectors and the outside temperature. The heat load generated by the cables does not have to be handled by the thermosiphon; these cables are directly connected to the condenser, which does handle this heat load. The goal is to have a small enough heat density at the surface of the open LN bath so that convective heat transfer occurs in the fluid with bubbles forming in the fluid rather than nucleation occurring on the metal wall of the Dewar. This condition is valid for free convection assuming the temperature difference is less than $2 \mathrm{~K}$. [Jin et al. 2009] provide data on heat-transfer coefficients for liquid nitrogen. These values are used to determine the surface area required for sufficient contact between the condenser and the open LN bath. Here we take a conservative number of $1.5 \mathrm{~K}$ for the difference in temperature and the material's heat transfer coefficient of $33 \mathrm{~W} / \mathrm{m}^{2}-\mathrm{K}$ to calculate the area required to dissipate $59.5 \mathrm{~W}$ total heat load (cable loads + detector module). The result is the area of a disk of radius $58.0 \mathrm{~cm}$ (22.8”). This is roughly the diameter of the LN Dewars proposed for the MJD, so no significant design change will be necessary.

In the event that all of the nitrogen boils off in the external Dewar, the temperature of the condenser end would rise. This would affect the heat capacity of the condenser, and will result in a temperature increase along the entire detector thermal path. The two-phase system will become an all-gas system. This situation must be avoided by regularly servicing the external nitrogen Dewar. For a 30-liter capacity, assuming a heat of vaporization for nitrogen at $80 \mathrm{~K}$ of $5.57 \mathrm{~kJ} / \mathrm{mol}$ [Span et al. 2000], the Dewar will need to be refilled at least every $50 \mathrm{hrs}$.

\subsection{Copper Growth Time}

The growth rate for electroformed copper is expected to be 0.002-0.003" per day [Aalseth 2007]. Assuming that the thickness of the thermosiphon wall is about 0.16 ” $(4 \mathrm{~mm})$, the growth time would be 1.7 to 2.7 months.

\subsection{Conclusions}

A previous technical report provided the experimental results for the current design of the thermosiphon for the Majorana Demonstrator [Fast et al. 2010]. Based on this design, a theoretical study of the feasibility of scaling this system up has been performed as described in this document. The thermosiphon's calculated heat load is increased $20 \%$, to a total heat load of $27.7 \mathrm{~W}$ per cryostat. The 
experimental setup [Fast et al. 2010] showed good performance in achieving a HPGe temperature and handling a heat load of up to $35 \mathrm{~W}$ for a 45 psig initial nitrogen load.. The thermal resistivity of the interfaces in the detector thermal path remains to be characterized. Minimal modifications will make the MJD thermosiphon suitable for the higher heat loads of the S4 cooling system. Depending on the results of the resistivity measurements, a modified contact for the cold-plate interface might be required to control the temperature drop across it. 


\subsection{References}

[Aalseth 2007] Aalseth CE. 2007. Ultra-High-Purity Copper Technology Update. Majorana Update to GERDA. Institute for Reference Materials and Measurements, June, 2007 Accessed April 1, 2011 at http://www.mpi-hd.mpg.de/ge76/geel07/geel07_slides/070612_aalseth.pdf

[Aalseth et al. 2009] Aalseth CE, M Amman, JF Amsbaugh, FT Avignone III, HO Back, AS Barabash, PS Barbeau, JR Beene, M Bergevin, FE Bertrand, M Boswell, V Brudanin, W Bugg, TH Burritt, Y-D Chan, JI Collar, RJ Cooper, R Creswick, JA Detwiler, PJ Doe, Y Efremenko, V Egorov, H Ejiri, SR Elliott, J Ely, J Esterline, H Farach, JE Fast, N Fields, P Finnerty, B Fujikawa, E Fuller, VM Gehman, GK Giovanetti, VE Guiseppe, K Gusey AL Hallin, R Hazama, R Henning, A Hime, EW Hoppe, TW Hossbach, MA Howe, RA Johnson, KJ Keeter, M Keillor, C Keller, JD Kephart, MF Kidd, O Kochetov, SI Konovalov, RT Kouzes, KT Lesko, L Leviner, JC Loach, PN Luke, S MacMullin, MG Marino, D-M Mei, HS Miley, M Miller, L Mizouni, A Montoya, AW Myers, M Nomachi, B Odom, JL Orrell, D Phillips, AWP Poon, G Prior, J Qian, DC Radford, K Rielage, RGH Robertson, L Rodriguez, KP Rykaczewski, AG Schubert, T Shima, M Shirchenko, J Strain, K Thomas, R Thompson, V Timkin, W Tornow, TD Van Wechel, I Vanyushin, K Vetter, R Warner, JF Wilkerson, JM Wouters, E Yakushev, AR Young, C-H Yu, V Yumatov, C Zhang, and S Zimmerman. 2009. "The MAJORANA DEMONSTRATOR: An R\&D project towards a tonne-scale germanium neutrinoless double-beta decay search.” Proceedings of the $10^{\text {th }}$ Conference of the Intersections of Particle and Nuclear Physics 1182, 88-91. Accessed April 1, 2011 at arXiv:0907.1581v1

[Brooks 2006] Brooks Automation, Inc. 2006. Helix Technology Model 1050 Cryodyne ${ }^{\circledR}$ Refrigeration System. Accessed April 1, 2011 at http://www.helixtechnology.com.

[Bush 2010] Private communication with Matthew Bush. Triangle Universities Nuclear Laboratory (TUNL). October 2010.

[Fast et al. 2010] Fast JE, DJ Reid, and E Aguayo Navarrete. 2010. Majorana Thermosyphon Prototype Experimental Results. PNNL-20065, Pacific Northwest National Laboratory, Richland, WA.

[Gilmore 2002] Gilmore, DG 2002 Spacecraft Thermal Control Handbook $2^{\text {nd }}$ ed. The Aeorspace Corporation.

[Lindeburg 2006] Lindeburg MR. 2006. Mechanical Engineering Reference Manual for the PE Exam, $11^{\text {th }}$ ed. Professional Publications, Inc.

[Luke 2010] Private communication with Paul Luke. LBNL. December 2010

[Miller 2010] Private communication with Mike Miller. University of Washington. December 2010

[Span et al. 2000] Span R, EW Lemmon, RT Jacobsen, W Wagner, and A Yokozeki. 2000. “A Reference Equation of State for the Thermodynamic Properties of Nitrogen for Temperatures from 63.151 to $1000 \mathrm{~K}$ and Pressures to 2200 MPa.” J. Phys. Chem. Ref. Data 29(6) 1361-1433. Accessed April 1, 2011 at http://jpcrd.aip.org/resource/1/jpcrbu/v29/i6/p1361 s1?isAuthorized=no

[Wolfram 2011] WolframMathWorld. 2011. Horizontal Cylindrical Segment. Accessed April 1, 2011 at http://mathworld.wolfram.com/HorizontalCylindricalSegment.html 


\section{Appendix A}

\section{Calculation of Radiated Heat Entering the S4 System from the Warm Cryostat Walls}





\section{Appendix A}

\section{Calculation of Radiated Heat Entering the S4 System from the Warm Cryostat Walls}

The net radiation emitted by the external vacuum jacket is given by equation 1[Gilmore 2002]. This equation is used under the following assumptions;

- Temperature are uniform over all surfaces

- The emmitance absorbance and transmittance of a surface are independent of wavelength and direction.

- All energy from a surface is emitted and reflected energy flux is uniform over each surface

- The view factor is assumed to be unity for the geometry discussed

$$
q_{\text {rad }}=\varepsilon \sigma T^{4} A_{c}
$$

where

$$
\begin{aligned}
\varepsilon & =\text { the emissivity of copper } \\
\sigma & =\text { the Stefan-Boltzmann constant }\left(5.67 \times 10^{-8} \mathrm{~W} / \mathrm{m}^{2}-\mathrm{K}^{4}\right) \\
T & =\text { the absolute temperature of the hot body }(\mathrm{K}) \\
A_{c} & =\text { the combined area of the surfaces exchanging heat }\left(\mathrm{m}^{2}\right)
\end{aligned}
$$

The outer cryostat wall is a cylindrical copper vessel. The inner detector structure is shielded from the radiated heat by a layer of copper. The distance between the outer wall and the heat shield is 1 inch; this space is evacuated. The heat radiated by the inner surface of the vacuum jacket onto the outer surface of the IR shield has a view factor close to unity (the volumes are very close to each other, and this geometry can be approximated as concentric spheres, for which the view factor is unity).

The total radiative heat exchange for the cryostat is the sum of all the contributions from the

cylindrical side walls and the top and bottom surfaces, $\mathrm{q}_{\text {Rad }}=\mathrm{q}_{\text {RadWalls }}+\mathrm{q}_{\text {RadTopPlate }}+\mathrm{q}_{\text {RadBottomPlate }}=8.3 \mathrm{~W}$

The heat entering the system is calculated under the following assumptions:

- Emissivity of copper $\varepsilon_{\text {copper }}=0.03$

- $\mathrm{T}=292 \mathrm{~K}$

- Length of the S4 cryostat is $0.43 \mathrm{~m}$ (17”)

- Diameter of the S4 cryostat is $0.43 \mathrm{~m}$ (17”) 



\section{Appendix B}

\section{Calculation of Conductive Heat Entering the System from the PEEK Supports}





\section{Appendix B}

\section{Calculation of Conductive Heat Entering the System from the PEEK Supports}

Calculating the heat conducted into the system via the PEEK supports is simple, assuming that any temperature dependence in the conductivity of the support material is negligible. The number of supports is derived from the latest MJD prototype cryostat cold-plate design; the total number of supports considered in this calculation is twice the number of supports for the MJD prototype cryostat. The temperatures of the warm end and the cold end are assumed constant at $300 \mathrm{~K}$ and $80 \mathrm{~K}$ respectively (i.e., no joint resistance); this is a very conservative assumption. Modifications to the material and geometry to reduce the mass of the supports are currently under consideration. Any future design will most likely entail less heat transfer, because use of less material will increase radiochemical purity.

Heat leaks through conductive paths can be calculated using Fourier's Law for heat conduction:

$$
q=\frac{k * \Delta T * A}{L}
$$

where

$$
\begin{aligned}
\mathrm{q} & =\text { the heat flow }(\mathrm{W}) \\
\mathrm{k} & =\text { the thermal conductivity }(\mathrm{W} / \mathrm{m}-\mathrm{K}) \\
\mathrm{A} & =\text { the area of the heat exchange surface }\left(\mathrm{m}^{2}\right) \\
\mathrm{L} & =\text { the length of the heat exchange volume }(\mathrm{m}) \\
\Delta \mathrm{T} & =\text { the temperature difference }(\mathrm{K})
\end{aligned}
$$

The heat entering the system is calculated under the following assumptions:

- Thermal conductivity of PEEK: $\mathrm{k}_{\text {PEEK }}($ room temperature $)=0.25 \mathrm{~W} / \mathrm{m}-\mathrm{K}$

- Maximum temperature difference: $\Delta \mathrm{T}=300-80=220 \mathrm{~K}$

- PEEK area (maximum contact area with cryostat wall), (2lateral + 6 vertical supports): $\mathrm{A}=8 \times$ $7.9 \times 10^{-6} \mathrm{~m}^{2}=6.3 \times 10^{-6} \mathrm{~m}^{2}$

- Length of warm-to-cold path: $\mathrm{L}=0.0064 \mathrm{~m}$ (0.25 in)

Conductive heat load through the two PEEK supports, $\mathrm{q}_{\mathrm{PEEK}}=0.5 \mathrm{~W}$ 

Appendix C

\section{Cable Heat Loads}





\section{Appendix C}

\section{Cable Heat Loads}

The thermal path between the detector module and the exterior via the wire leads connecting the FEE represents a conductive heat leak into the cryostat. The current plans for the MJD have one high-voltage (HV) wire per detector (35/cryostat) at approximately 0.025" diameter, and four signal wires per detector (140/cryostat) at approximately 0.003" diameter [Bush 2010].

Heat leaks through conductive paths can be calculated using Fourier's Law for heat conduction, given in Equation (B.1). The dimensions (length and cross-sectional area) of the wire, as well as the properties of the wire material are:

$$
\begin{aligned}
\mathrm{L}_{\text {HVwire }} & =100 \mathrm{~mm} \\
\mathrm{~A}_{\text {HVwire }} & =0.317 \mathrm{~mm}^{2}\left(\text { diameter of wire, } \mathrm{d}_{\text {wire }}=0.025 \mathrm{in}^{2}\right) \\
\mathrm{L}_{\text {SIGNALwire }} & =100 \mathrm{~mm} \\
\mathrm{~A}_{\text {SIGNALwire }} & =0.063 \mathrm{~mm}^{2}\left(\mathrm{~d}_{\text {wire }}=0.005 \mathrm{in}^{2}\right)
\end{aligned}
$$

The heat entering the system is calculated under the following assumptions:

- The wires are made of copper, with a thermal conductivity of $\mathrm{k}_{\text {copper }}$ (room temperature) $=355 \mathrm{~W} / \mathrm{m}-\mathrm{K}$

- Maximum temperature difference: $\Delta \mathrm{T}=300-78=222 \mathrm{~K}$

- Each detector channel has one HV wire and four signal wires, resulting in a total of $95 \mathrm{HV}$ wires and 380 signal wires for the S4 experiment.

Conductive heat load through the HV cables, $\mathrm{q}_{\text {cable loads }}=\mathrm{q}_{\mathrm{HVwire}}+\mathrm{q}_{\text {signalWire }}=23.4+18.9=32.3 \mathrm{~W}$ 



\section{Appendix D}

Convective Heat Transfer Calculations for the Thermosiphon Experimental Setup 



\section{Appendix D}

\section{Convective Heat Transfer Calculations for the Thermosiphon Experimental Setup}

The motion of the fluids (liquid and gas) inside the thermosiphon will be analyzed in this section.

\section{D.1 Mass flow}

The mass flow (MF) of nitrogen can be determined from the power dissipation required on the thermosiphon and the heat of vaporization of nitrogen:

$$
M F=\frac{q}{H_{\text {vap }} / \rho}
$$

where

$$
\begin{aligned}
\mathrm{q} & =\text { dissipated heat } \\
\mathrm{H}_{\text {vap }} & =\text { heat of vaporization for nitrogen }(5.56 \mathrm{~kJ} / \mathrm{mol}) \\
\rho & =\text { density of liquid nitrogen }(28.01 \mathrm{~g} / \mathrm{mol})
\end{aligned}
$$

For a heat load of 25 Watts the result is MF $=1.26 \times 10^{-4} \mathrm{~kg} / \mathrm{s}$.

\section{D.2 Reynolds Number}

The type of flow (laminar or turbulent) for different configurations of fluid in motion relative to a surface is indicated by the Reynolds number, Re:

$$
R e=\frac{\rho V D_{\mathrm{H}}}{\mu}
$$

where $\quad \rho=$ the density of the fluid $\left(\mathrm{kg} / \mathrm{m}^{3}\right)$

$\mathrm{V}=$ the fluid velocity $(\mathrm{m} / \mathrm{s})$

$\mathrm{D}_{\mathrm{H}}=$ the hydraulic diameter of the pipe (m)

$\mu=$ the dynamic viscosity of the fluid $(\mathrm{Pa} \cdot \mathrm{s})$

The Reynolds number for the gas phase in the thermosiphon evaporator tube is calculated under the following assumptions:

- The gas is at $80 \mathrm{~K}$ with a density of $4.61 \mathrm{~kg} / \mathrm{m}^{3}$ and dynamic viscosity of $5.27 \times 10^{-6} \mathrm{~Pa}-\mathrm{sec}$

- Gas occupies $90 \%$ of the area of the evaporator cross section and the wetted length includes both the tube wall and the liquid surface, resulting in a hydraulic diameter of $2.35 \mathrm{~cm}$

- The fluid velocity of $0.06 \mathrm{~m} / \mathrm{s}$ is based on transport of sufficient nitrogen $\left(1.26 \times 10^{-4} \mathrm{~kg} / \mathrm{s}\right)$ to remove $25 \mathrm{~W}$ of heat via vaporization

The result is $R e_{\text {gas }}=1232$. When the value of the Reynolds number is below 2300 , the system is considered to have laminar flow. The transition to turbulent flow will occur at approximately 47 Watts of heat load for this tube size, nitrogen temperature, and nitrogen liquid level. As the liquid level in the tube 
increases, the flow velocity increases and the hydraulic diameter decreases. For example, when the thermosiphon tube is half filled with liquid, the Reynolds number will increase by $18.8 \%$ and the critical heat load when the gaseous flow transitions from laminar to turbulent flow drops to approximately 39 Watts, still well above the heat load expected for the Majorana Demonstrator.

The Reynolds number for the liquid flow is determined based on the following assumptions:

- The liquid is at $80 \mathrm{~K}$ with a density of $808 \mathrm{~kg} / \mathrm{m}^{3}$ and dynamic viscosity of $1.58 \times 10^{-4} \mathrm{~Pa}-\mathrm{sec}$

- $10 \%$ of the area of the evaporator cross section is occupied by the liquid and the wetted length is only the contact area with the tube wall, resulting in a hydraulic diameter of $0.98 \mathrm{~cm}$

- The fluid velocity of $3.09 \times 10^{-3} \mathrm{~m} / \mathrm{s}$ is based on transport of sufficient nitrogen $\left(1.26 \times 10^{-4} \mathrm{~kg} / \mathrm{s}\right)$ to remove $25 \mathrm{~W}$ of heat via heat of vaporization

The result is $R e_{\text {liquid }}=155$. As expected, the liquid flow is laminar.

\section{D.3 Prandtl Number}

The Prandtl number is a dimensionless number approximating the ratio of momentum diffusivity (kinematic viscosity) and thermal diffusivity. It is defined as:

$$
\operatorname{Pr}=\frac{C_{p} \mu}{\kappa}
$$

where

$$
\begin{aligned}
\mu & =\text { the dynamic viscosity }(\mathrm{Pa}-\mathrm{s}) \\
\kappa & =\text { the thermal conductivity }(\mathrm{W} /(\mathrm{K}-\mathrm{m})) \\
\mathrm{c}_{\mathrm{p}} & =\text { the specific heat }(\mathrm{J} /(\mathrm{kg}-\mathrm{K}))
\end{aligned}
$$

The Prandtl number for the gas phase is determined based on the following assumptions:

- The gas is at $80 \mathrm{~K}$ and 14.5 psia with a thermal conductivity of $8.0 \times 10^{-3} \mathrm{~W} / \mathrm{kg}-\mathrm{m}$, a dynamic viscosity of $5.6 \times 10^{-6} \mathrm{~Pa}-\mathrm{sec}$ and a specific heat of $2.1 \times 10^{-3} \mathrm{~J} / \mathrm{kg} \mathrm{K}$ [Span et al. 2000]

The result is $P r_{\text {gas }}=1.47 \times 10^{-6}$. For nitrogen gas at $80 \mathrm{~K}$, heat conduction is very effective compared to convection: thermal diffusivity is dominant. 
Appendix E

Fluid Volume in the Copper Pipe 



\section{Appendix E}

\section{Fluid Volume in the Copper Pipe}

The amount of nitrogen in the system remains constant. The ideal gas law was used to calculate the number of moles of nitrogen the system contains under the initial conditions from [Fast et al. 2010]:

$$
\mathrm{PV}=\mathrm{nRT}
$$

where

$$
\begin{aligned}
\text { pressure, } \mathrm{P} & =49 \mathrm{psig}=53.7 \mathrm{psia}=3.7 \mathrm{~atm} \\
\text { gas constant, } \mathrm{R} & =0.082 \mathrm{l} \mathrm{atmK} \mathrm{mol}^{-1} \\
\text { temperature, } \mathrm{T} & =292 \mathrm{~K} \\
\text { volume, } \mathrm{V} & =37.8 \mathrm{l}
\end{aligned}
$$

The result is a total nitrogen content of $\mathrm{n}_{\text {Total }}=5.84$ moles.

During operation the temperature drops once the cold head starts working; an equilibrium state is reached in which the liquid and vapor phases coexist. Assuming that the nitrogen vapor remains at room temperature (the gas ballast tank is not cooled and dominates the total gas volume of the system), the amount of nitrogen in vapor phase can be derived from the pressure of the system using the ideal gas law:

$$
\begin{aligned}
\mathrm{P} & =4 \mathrm{psig}=18.7 \mathrm{psia}=1.3 \mathrm{~atm} \\
\mathrm{R} & =0.082 \mathrm{latm} \mathrm{K} \mathrm{mol}^{-1} \\
\mathrm{~T} & =292 \mathrm{~K} \\
\mathrm{~V} & =37.8 \mathrm{l}
\end{aligned}
$$

The resulting nitrogen vapor content is $n_{\text {vapor }}=2.05$ moles, and hence the remainder, 3.79 moles, is liquid.

Assuming that this amount of liquid sits completely in the evaporator tube, the volume of the liquid can be derived using the density of nitrogen $\left(\mathrm{D}_{\mathrm{LN}}\right)$;

$$
\begin{aligned}
\mathrm{D}_{\mathrm{LN}}(82 \mathrm{~K}) & =28.85 \mathrm{~mol} / \mathrm{l} \\
\mathrm{V}_{\text {nitrogen }} & =0.13 \mathrm{l}
\end{aligned}
$$

The total volume of the evaporator tube is $1.06 \times 3.1416 \times 0.0254^{2} \mathrm{~m}^{3}=2.059$ l, so the liquid occupies $6.4 \%$ of the volume of the evaporator tube under these conditions.

The solid cut from a horizontal cylinder of length $L$ and radius $R$ by a single plane oriented parallel to the cylinder's axis of symmetry (i.e., a portion of a horizontal cylindrical tank that is partially filled with fluid) follows Equation (E.2), taken from [Wolfram 2011].

$$
V=L\left[R^{2} \cos ^{-1}\left(\frac{R-h}{R}\right)-(R-h) \sqrt{2 R h-h}\right]
$$

Depth of fluid, $\mathrm{h} \approx 0.0035 \mathrm{~m}=0.1$ inches 
The fluid depth was approximately $11.5 \%$ of the evaporator tube diameter. 


\section{Distribution}

No. of

Copies

\# Name

Organization

Address

City, State and ZIP Code

\# Organization

Address

City, State and ZIP Code

Name

Name

Name

Name

Name (\#)

\# Name

Organization

Address

City, State and ZIP Code
No. of

Copies

\# Foreign Distribution

\# Name

Organization

Address

Address line 2

COUNTRY

\# Local Distribution

Pacific Northwest National Laboratory

Name

Name

Name

Name

Name
Mailstop

Mailstop

Mailstop

Mailstop

(PDF) 




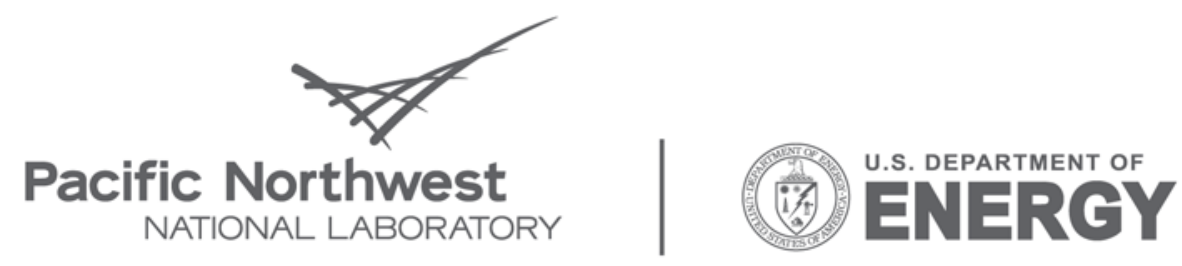

Proudly Operated by Battelle Since 1965

902 Battelle Boulevard

P.O. Box 999

Richland, WA 99352

1-888-375-PNNL (7665)

www.pnl.gov 